\title{
New Experimental Evidence for Thermodynamic Links to the \\ Kinetic Fragility of Glass-forming Polymers
}

Guozhang $\mathrm{Wu}^{*}$, Yuanbiao Liu, Gaopeng Shi

Shanghai Key Laboratory of Advanced Polymeric Materials, School of Materials Science \& Engineering,

1 Homopolymers

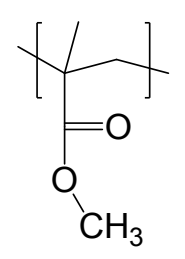

PMMA<smiles>CC(C)(C)CC(C)(C)c1ccccc1</smiles>

PS<smiles>COC(=O)CC(C)(C)CC(C)(C)C</smiles>

PMA<smiles>CC(C)(C)CC(C)(C)C(C)(C)C</smiles>

PIB<smiles>CCOC(=O)C(C)CC(C)(C)C</smiles>

PEA<smiles>CC(C)(C)Oc1ccc(C(C)(C)c2ccc(OCC3CCCO3)cc2)cc1</smiles>

PC

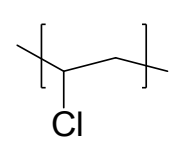

PVC

PIP

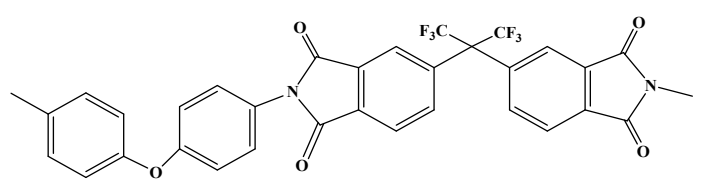

PI

2 Copolymers

(1) P(St-EA) copolymers

$\mathrm{P}(\mathrm{St}-\mathrm{EA})$ copolymers with mass ratio St/EA of $1: 2,1: 1$ and $2: 1$ are denoted as $\mathrm{P}(\mathrm{St}-\mathrm{EA} / 1: 2)$, $\mathrm{P}(\mathrm{St}-\mathrm{EA} / 1: 1)$ and $\mathrm{P}(\mathrm{St}-\mathrm{EA} / 2: 1)$, respectively.

*Corresponding author: G. Wu, E-mail: wgz@ecust.edu.cn 


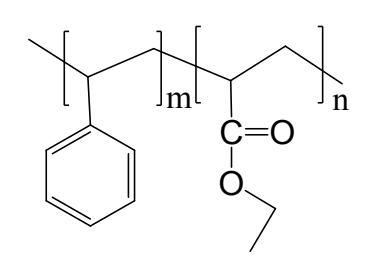

(2) AR-51 and AR-72LS rubbers

AR-51 is composed of about $98 \mathrm{~mol} \%$ ethyl acrylate and 2 mol\% Glycidyl methacrylate, which is described as below. The structure of AR-72LS remains unknown.

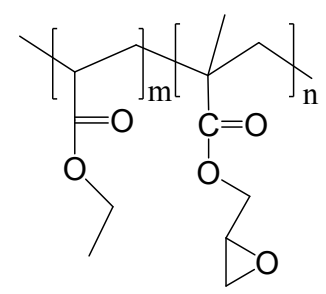

(3) IC-PC and IT-PC Polycarbonates

IC-PC is composed of $70 \mathrm{~mol} \%$ isosorbide and $30 \mathrm{~mol} \%$ 1,4-cyclohexanedimethanol, which is described as:

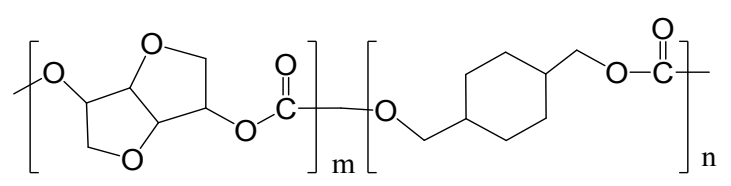

IT-PC is composed of $70 \mathrm{~mol} \%$ isosorbide and $30 \mathrm{~mol} \%$ tricyclodecanedimethanol, which is described as:

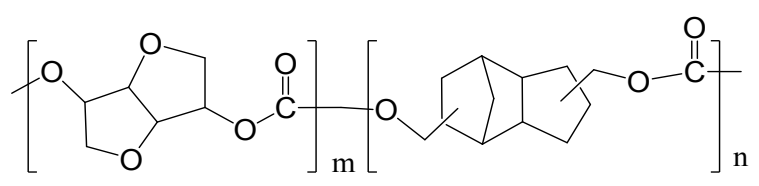

3 Small molecules
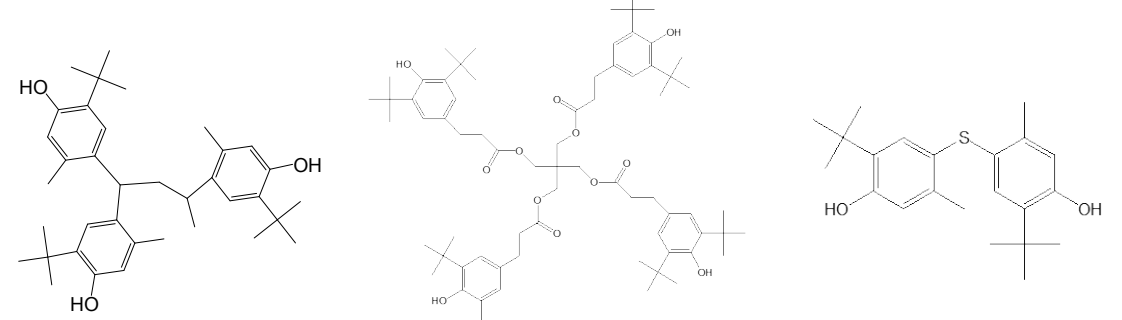<smiles>OCC(O)C(O)C(O)CO</smiles> 
4 Coincidence between $T_{\mathrm{f}}^{\prime}$ and onset $T_{\mathrm{g}}$ value

Figure S1 shows the correlation between limiting fictive temperature $\left(T_{\mathrm{f}}^{\prime}\right)$ and onset $T_{\mathrm{g}}$ value obtained from $\pm 10 \mathrm{~K} / \mathrm{min}$ for various glass formers, including PIB, PIP, PEA, PMA, PVAc, PS, PMMA, PC, and PI. As revealed, $T_{\mathrm{f}}^{\prime}$ varies proportionally with increasing onset $T_{\mathrm{g}}$ value in a slope of 1 , suggesting a good coincidence between the two quantities.

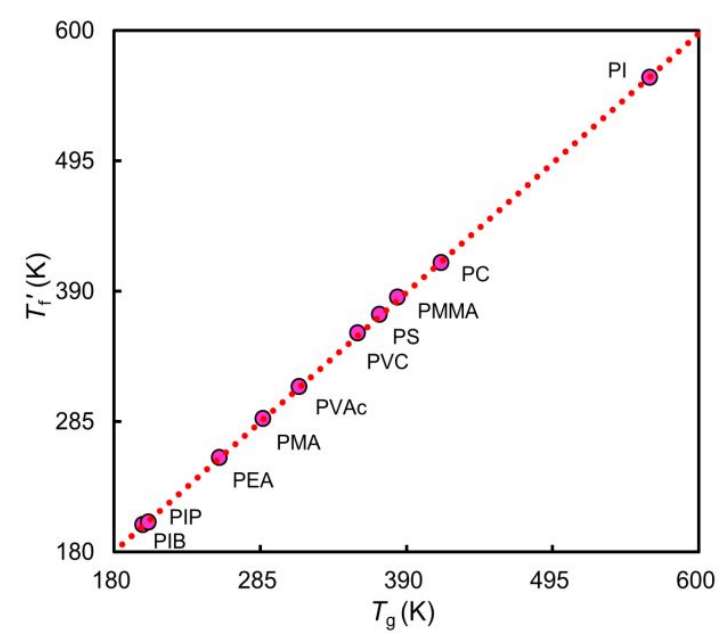

Figure S1. Correlation between limiting fictive temperature $\left(T_{\mathrm{f}}^{\prime}\right)$ and onset $T_{\mathrm{g}}$ values for various glass formers obtained from $\pm 10 \mathrm{~K} / \mathrm{min}$

5 Mechanism for hysteresis in enthalpy

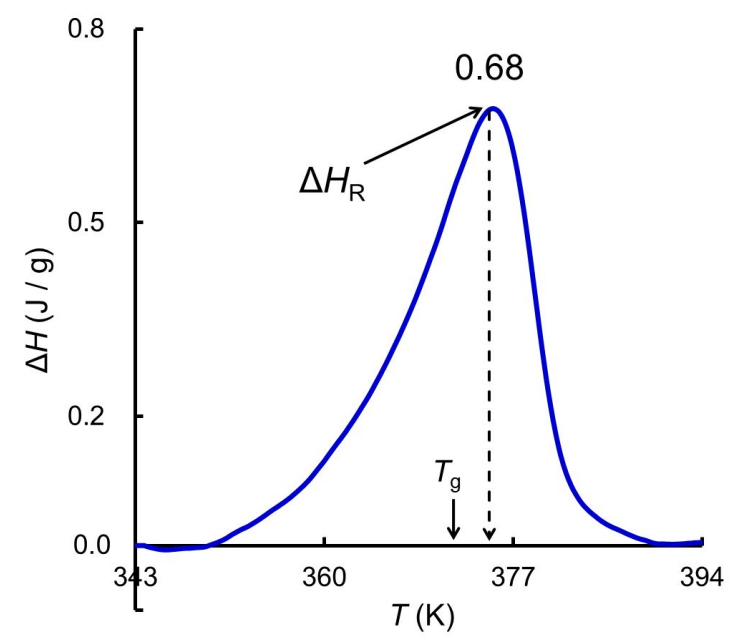

Figure S2. Determination of relaxed enthalpy $\Delta H_{\mathrm{R}}$ from the heat capacity $\left(C_{\mathrm{p}}\right)$ curves at $\pm 10 \mathrm{~K} / \mathrm{min}$ in Figure 1 a for PS $\left(M_{\mathrm{n}}=65,000, \mathrm{PDI}=2.8\right)$. The solid and dashed arrows point to the onset $T_{\mathrm{g}}(=371 \mathrm{~K})$ and the temperature $(T=375 \mathrm{~K})$ for maximum $\Delta H$ of PS sample, respectively. 
The hysteresis in enthalpy in a standard $\pm 10 \mathrm{~K} / \mathrm{min}$ cooling/reheating cycle can be quantified by the enthalpy difference between cooling and heating curves: $\Delta H=H_{\text {cool }}(T)-$ $H_{\text {heat }}(T) . \Delta H$ is a thermodynamic quantity proportional to the driving force for glass equilibration. In general, $\Delta H$ remains at 0 at liquid state $\left(>T_{\mathrm{g}}\right)$ or at glassy state $\left(<T_{\mathrm{g}}\right)$ (Figure S2), where there is no thermodynamic driving force for relaxation, because the relaxation dynamics follow instantaneously the imposed temperature fluctuations at liquid state (so-called metastable equilibrium) or is completely frozen at glassy state. Eventually, the hysteresis in enthalpy can only reach a maximum value (so-called hysteresis enthalpy or relaxed enthalpy $\left.\Delta H_{\mathrm{R}}\right)$ in the vicinity of $T_{\mathrm{g}}{ }^{1}(=371 \mathrm{~K}$ for PS) (Figure $\mathrm{S} 2)$, where the relaxation time becomes comparable to the typical observation time (100 s).

$6 \Delta H_{\mathrm{R}}$ obtained from $\pm 10 \mathrm{~K} / \mathrm{min}$ and $\pm 20 \mathrm{~K} / \mathrm{min}$
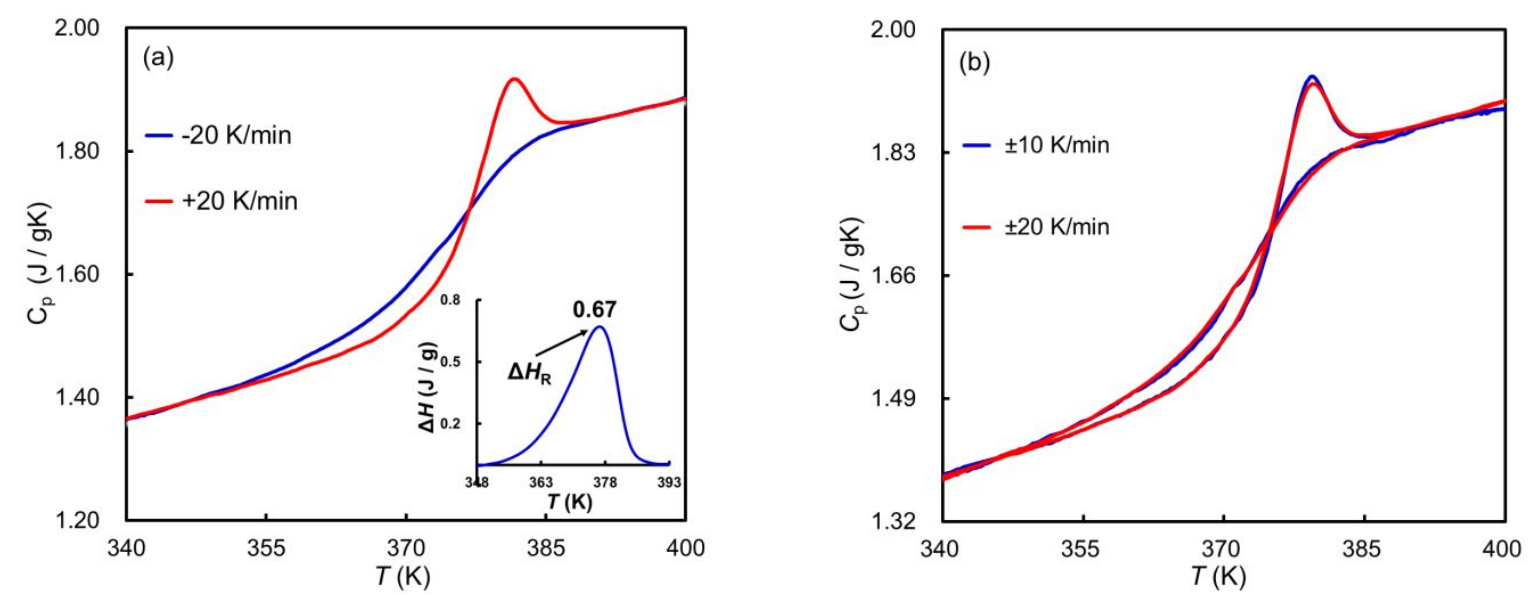

Figure S3. (a) Heat capacity $C_{\mathrm{p}}$ curves of PS $\left(M_{\mathrm{n}}=65,000, \mathrm{PDI}=2.8\right)$ obtained from $\pm 20 \mathrm{~K} / \mathrm{min}$. The relaxed enthalpy $\Delta H_{\mathrm{R}}$ is depicted in the insets of (a). (b) Comparison between the $C_{\mathrm{p}}$ peaks obtained from $\pm 10 \mathrm{~K} / \mathrm{min}$ and $\pm 20 \mathrm{~K} / \mathrm{min}$. The $C_{\mathrm{p}}$ peaks obtained from $\pm 20 \mathrm{~K} / \mathrm{min}$ are vertically and horizontally shifted by using the $C_{\mathrm{p}}$ peaks at $\pm 10 \mathrm{~K} / \mathrm{min}$ as a reference.

Figure S3a shows the heat capacity $C_{\mathrm{p}}$ curves of PS $\left(M_{\mathrm{n}}=65,000, \mathrm{PDI}=2.8\right)$ obtained from $\pm 20 \mathrm{~K} / \mathrm{min}$. The relaxed enthalpy $\Delta H_{\mathrm{R}}$ is calculated from the maximum enthalpy difference between cooling and reheating circles, and is depicted in the inset of Figure S3a. The $T_{\mathrm{g}}$ value (at the onset point) obtained from $\pm 20 \mathrm{~K} / \mathrm{min}$ is $1.5 \mathrm{~K}$ higher than that obtained from \pm 10 $\mathrm{K} / \mathrm{min}$. This is consistent with the widely accepted notion that $T_{\mathrm{g}}$ increases with increasing cooling/heating rates. We found that the values of $\Delta H_{\mathrm{R}}$ and $\Delta C_{\mathrm{p}}$ obtained from $\pm 10 \mathrm{~K} / \mathrm{min}$ is respectively $0.68 \mathrm{~J} / \mathrm{g}$ and $0.29 \mathrm{~J} / \mathrm{gK}$, which are slightly higher than those obtained from \pm 20 
$\mathrm{K} / \mathrm{min}$ in Figure $\mathrm{S} 3 \mathrm{a}\left(\Delta H_{\mathrm{R}}=0.67 \mathrm{~J} / \mathrm{g}, \Delta C_{\mathrm{p}}=0.29 \mathrm{~J} / \mathrm{gK}\right)$.

Figure S3b compares the $C_{\mathrm{p}}$ peaks of PS obtained from $\pm 10 \mathrm{~K} / \mathrm{min}$ and $\pm 20 \mathrm{~K} / \mathrm{min}$. The $C_{\mathrm{p}}$ peaks obtained from $\pm 20 \mathrm{~K} / \mathrm{min}$ are vertically and horizontally shifted by using the $C_{\mathrm{p}}$ peaks at $\pm 10 \mathrm{~K} / \mathrm{min}$ as a reference. Evidently, the $C_{\mathrm{p}}$ peaks at those cooling/reheating rates can well superpose, further confirm that the thermal treatment of $\pm 10 \mathrm{~K} / \mathrm{min}$ and $\pm 20 \mathrm{~K} / \mathrm{min}$ slightly changed the temperature position of the $C_{\mathrm{p}}$ peaks and hysteresis area $\Delta H_{\mathrm{R}}$.

\section{REFERENCES}

1. Liu, Z.; Hu, Y.; Li, X.; Song, W.; Goyal, S.; Micoulaut, M.; Bauchy, M. Glass relaxation and hysteresis of the glass transition by molecular dynamics simulations. Phys. Rev. B 2018, 98, 104205. 